\title{
Burgers over kernwaarden en kerntaken huisarts
}

Anne Brabers, Niek de Wit, Bart Meijman, Judith de Jong

Inleiding Op initiatief van partijen binnen de huisartsenzorg zijn in 2018 de kernwaarden en kerntaken van de huisarts[enzorg] herijkt. In dit artikel staat de vraag centraal hoe burgers aankijken tegen die kernwaarden en kerntaken.

Methode Als onderdeel van het herijkingsproces hebben we met behulp van het Consumentenpanel Gezondheidszorg van het Nivel een online enquête afgenomen onder burgers.

Resultaten De enquête is ingevuld door 753 panelleden [respons 50,2\%]. Uit de resultaten blijkt dat burgers over het algemeen ruim tevreden zijn over de huidige huisartsenzorg. Zo geven de respondenten gemiddeld een 8,2 als rapportcijfer aan de kwaliteit van zorg door hun huisarts. Ook zijn bijna negen op de tien respondenten tevreden met de openingstijden van hun huisartsenpraktijk. Wat betreft de kernwaarden vinden respondenten het vooral belangrijk dat huisartsen deskundig en betrokken zijn en dat ze hun patiënten kennen. Preventie en eerste aanspreekpunt zijn voor mensen met vragen over sociale problematiek beschouwen de respondenten minder als kerntaken van de huisarts.

Conclusie De opvattingen van burgers sluiten aan bij de herijkte kernwaarden en kerntaken van de huisarts[enzorg].

\section{INLEIDING}

In de afgelopen jaren hebben verschillende (maatschappelijke) ontwikkelingen en hervormingen binnen de gezondheidszorg plaatsgevonden die directe gevolgen hebben voor het takenpakket van huisartsen. Deze ontwikkelingen vergroten de druk op de huisartsenzorg. Daarom heeft een groot aantal bij de huisartsenzorg betrokken partijen het initiatief genomen om de kernwaarden en kerntaken van de huisarts(enzorg) te herijken, om zo de huisartsenzorg toekomstbestendig te houden. De herijkte kernwaarden en -taken zijn gepresenteerd op 21 januari 2019 in Woudschoten, waar precies zestig jaar geleden de basis werd gelegd voor de huidige taakomschrijving voor de huisartsenzorg. Het herijkingsproces bestond uit een uitvoerige uitvraag onder de beroepsgroep, onder andere door denksessies met leden uit de beroepsgroep en een online enquête onder huisartsen. Als onderdeel van het proces is ook een online enquête onder burgers afgenomen. De resultaten hiervan staan centraal in dit artikel; het volledige verslag van de resultaten is elders te vinden. ${ }^{1}$ Wat vinden burgers de belangrijkste kernwaarden van de huisarts en wat beschouwen zij als de kerntaken van de huisarts? En welke taken kunnen volgens burgers, als er gekozen moet worden, eventueel door anderen dan de huisarts worden gedaan? In dit artikel beantwoorden we deze vragen en bespreken we hoe de visie van burgers aansluit bij de herijkte kernwaarden en kerntaken. Dit artikel is onderdeel van een serie artikelen over het herijken van de kernwaarden en kerntaken van de huisarts(enzorg).

\section{METHODE}

\section{Consumentenpanel Gezondheidszorg}

In de periode tussen 22 november en 16 december 2018 hebben we een online enquête afgenomen onder burgers met behulp van het Nivel Consumentenpanel Gezondheidszorg [kader]. De enquête is verstuurd naar een steekproef van 1500 panelleden, representatief voor de algemene bevolking in Nederland van achttien jaar en ouder naar leeftijd en geslacht. De panelleden die niet reageerden, kregen in totaal drie online herinneringen. De enquête is ingevuld door 753 panelleden (een respons van $50,2 \%)$.

\section{Online enquête}

Centraal in de burgerenquête stonden de kernwaarden 
HET NIVEL CONSUMENTENPANEL GEZONDHEIDSZORG Het Nivel Consumentenpanel Gezondheidszorg peilt hoe burgers in Nederland denken over de gezondheidszorg en wat hun ervaringen zijn met die zorg. Ten tijde van het huidige onderzoek bestond het panel uit ongeveer 12.000 personen van achttien jaar en ouder. Van ieder panellid is een groot aantal achtergrondkenmerken bekend. $0 \mathrm{~m}$ natuurlijk verloop [bijvoorbeeld het overlijden van panelleden] te compenseren wordt het panel op regelmatige basis aangevuld en vernieuwd. Ook worden panelleden die langer lid zijn van het panel uitgeschreven om leereffecten te voorkomen. Het werven van nieuwe panelleden gebeurt via de aankoop van adresbestanden en via huisartsenpraktijken die deelnemen aan Nivel Zorgregistraties eerste lijn. Burgers kunnen zich niet zelf aanmelden voor het panel. De panelleden krijgen gemiddeld drie tot vier keer per jaar een vragenlijst toegestuurd over actuele en beleidsrelevante thema's binnen de gezondheidszorg. Meer informatie over het panel is te vinden in het basisrapport. ${ }^{2}$

en -taken van de huisarts(enzorg). Daarnaast bevatte deze onder andere vragen over de tevredenheid van burgers over de huisartsenzorg. Onderzoekers van het Nivel (twee van de auteurs, $A B$ en JdJ) hebben de enquête voor burgers opgesteld in samenwerking met enkele huisartsen uit de stuurgroep van het project Toekomst Huisartsenzorg (de andere twee auteurs, $\mathrm{NdW}, \mathrm{BM}$ ). De enquête onder huisartsen vormde hierbij het uitgangspunt, waarbij we vragen uit deze enquête hebben 'vertaald' naar vragen voor burgers.

Wat betreft de tevredenheid over de huisartsenzorg hebben we onder andere vragen opgenomen over de tevredenheid met de openingstijden van de praktijk en de mate waarin burgers snel genoeg terecht kunnen bij hun huisartsenpraktijk, en meer specifiek de huisarts van hun voorkeur. Ook hebben we de respondenten gevraagd een rapportcijfer (van 1 tot 10) te

\section{De opvattingen van burgers sluiten aan bij de herijkte kernwaarden en kern- taken van de huisarts[enzorg]}

geven voor een aantal aspecten van de huisartsenzorg. Wat betreft de kernwaarden hebben we de respondenten zeventien verschillende aspecten van het werk van huisartsen in Nederland voorgelegd. De respondenten mochten hieruit maximaal vijf aspecten kiezen en moesten deze rangschikken van 1 tot 5 , waarbij 1 het aspect is wat zij het belangrijkst vinden. We hebben de respondenten vervolgens uitgelegd dat het vak van huisarts heel breed is en dat de huisarts niet alles zelf kan doen. Dit betekent dat soms besloten moet worden wat de huisarts doet en wat anderen doen. De panelleden kregen tien kerntaken voorgelegd en we vroegen ze welke van deze kerntaken anderen zouden kunnen uitvoeren wanneer de huisarts niet voldoende tijd heeft. De respondenten mochten maximaal drie taken uitkiezen. Daarnaast hebben we ze nog zestien stellingen over de kernwaarden en -taken voorgelegd, waarbij de respondenten moesten aangeven of ze het met de stellingen eens of oneens waren. Tot slot kregen de respondenten vragen over de beschikbaarheid van de huisartsenzorg voor zowel niet-spoedeisende als spoedeisende vragen, en voor terminaal-palliatieve zorg.

\section{Statistische analyses}

Acht van de 753 respondenten stonden niet ingeschreven bij een vaste huisartsenpraktijk. Deze acht deelnemers lieten we buiten de analyses, omdat veel vragen gingen over de eigen huisarts(praktijk) en ze deze niet konden invullen. We voerden de analyses dus uit op de gegevens van 745 respondenten. Deze groep respondenten was naar leeftijd en geslacht niet helemaal representatief voor de algemene bevolking van achttien jaar en ouder, ook al was de steekproef dit wel. Dit komt omdat ouderen relatief vaker hebben deelgenomen dan jongeren. We pasten een weging toe om hiervoor te corrigeren, waarbij de gebruikte weegfactoren varieerden van 0,54 tot 2,11 . De beschrijvende analyses voerden we uit met STATA, versie 15.0 .

\section{RESULTATEN}

\section{Beschrijving van de respondenten}

De helft van de respondenten was vrouw en de gemiddelde leeftijd was 58 jaar (spreiding 25-89 jaar). De meerderheid $(85,0 \%)$ van de respondenten gaf aan langer dan vijf jaar te staan ingeschreven bij hun huisartsenpraktijk. Van de respon-

\section{WAT IS BEKEND?}

- In 2018 zijn de kernwaarden en kerntaken van de huisarts[enzorg] herijkt.

- Onderdeel van dit proces was een online enquête onder burgers die inzicht moest geven in de manier waarop zij aankijken tegen de kernwaarden en kerntaken van de huisarts[enzorg].

\section{WAT IS NIEUW?}

- Uit de resultaten blijkt dat burgers over het algemeen ruim tevreden zijn over de huidige huisartsenzorg.

- Ook vinden burgers het belangrijk dat huisartsen deskundig en betrokken zijn. Sociale problematiek en preventie zien ze minder als taak van huisartsen.

- Deze opvattingen van burgers sluiten aan bij de herijkte kernwaarden en kerntaken van de huisarts[enzorg].

- Burgers vinden wel vaker dan huisartsen dat de huisarts persoonlijk voor terminale zorg beschikbaar moet zijn. 
denten gaf $81,8 \%$ aan in de afgelopen twaalf maanden voor zichzelf contact te hebben gehad met hun huisartsenpraktijk; $23,2 \%$ had voor zichzelf contact opgenomen met de huisartsenpost.

\section{Tevredenheid over de huisartsenzorg}

Negen op de tien $(88,3 \%)$ respondenten gaf aan tevreden te zijn met de openingstijden van hun huisartsenpraktijk. Een deel van degenen die niet tevreden zijn, wilde een avondopenstelling (5,7\%). Een aantal respondenten noemde andere redenen waarom ze niet tevreden zijn, zoals het feit dat er geen inloopspreekuur meer is en dat de praktijk vaak gesloten is in verband met vakantie.

Uit [figuur 1] blijkt dat ruim de helft (55,8\%) meestal of altijd bij dezelfde huisarts binnen de praktijk komt. Bijna negen op de tien $(87,6 \%)$ gaf aan dat ze bij een klacht die voor hen belangrijk is meestal of altijd terecht kunnen bij de huisarts van hun voorkeur. Ook zei 91,6\% meestal of altijd snel genoeg terecht te kunnen bij de huisartsenpraktijk voor een klacht die voor hen belangrijk is.

De respondenten gaven gemiddeld een 8,2 voor de kwaliteit van zorg door hun huisarts (op een schaal van 1 tot 10). De kwaliteit van de zorg op de huisartsenpost kreeg van de respondenten gemiddeld een 7,5 als rapportcijfer en de huisartsenzorg in Nederland in het algemeen een 7,7.

\section{Kernwaarden en kerntaken}

Met betrekking tot de kernwaarden van de huisarts(enzorg) gaven respondenten aan het vooral belangrijk te vinden dat huisartsen deskundig en betrokken zijn en dat ze hun patiënten kennen [figuur 2]. Ook vonden respondenten het be- langrijk dat alle mensen naar een huisarts kunnen gaan en ze wanneer dat nodig is kunnen rekenen op de huisarts.

Ook vinden bijna alle respondenten dat het een goede zaak is als hun huisarts meedoet aan het opleiden van nieuwe huisartsen en aan wetenschappelijk onderzoek: 96,0\% was het eens met de stelling 'Ik vind het een goede zaak dat mijn huisarts meedoet aan het opleiden van nieuwe huisartsen' en 92,8\% was het eens met de stelling 'Ik vind het een goede zaak dat mijn huisarts meedoet aan wetenschappelijk onderzoek dat van belang is voor de huisartsenzorg'.

\section{Burgers gaven gemiddeld een 8,2 voor de kwaliteit van zorg door hun huisarts}

[Figuur 2] laat ook zien dat respondenten aangaven het het minst belangrijk te vinden dat huisartsen betrokken zijn bij problemen in de samenleving, dat zij zelf kunnen kiezen hoeveel uren zij werken en dat zij zich specialiseren (bijvoorbeeld in kleine operaties).

Uit [figuur 3] blijkt dat bijna zes op de tien $(58,2 \%)$ respondenten vonden dat, wanneer de huisarts niet voldoende tijd heeft, anderen dan de huisarts eerste aanspreekpunt kunnen zijn voor mensen met vragen over sociale problematiek. Ook preventie zien de respondenten als een taak die anderen kunnen uitvoeren. Ongeveer een derde vond dat taken, zoals het voorkomen dat gezonde mensen ziek worden en adviseren over gezondheid en leefstijl door anderen kunnen worden uitgevoerd.

\section{Figuur 1}

\section{Drie vragen over terecht kunnen bij de huisarts}

Hoe vaak komt u bij dezelfde huisarts binnen uw huisartsenpraktijk? ( $n=731$, gewogen)

Hoe vaak kunt u bij een klacht die voor $\mathrm{u}$ belangrijk is terecht bij de huisarts van uw voorkeur, binnen uw huisartsenpraktijk? ( $n=735$, gewogen)

Kunt $\mathrm{u}$ bij een klacht die voor $\mathrm{u}$ belangrijk is snel genoeg terecht bij uw huisartsenpraktijk? ( $n=734$, gewogen)

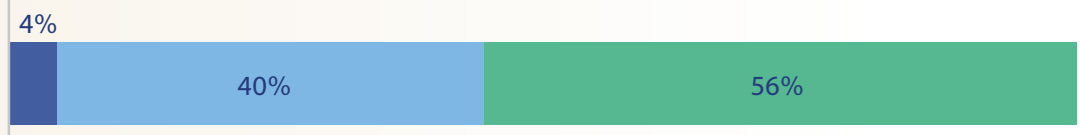

$2 \%$

$10 \%$ $88 \%$ $2 \%$

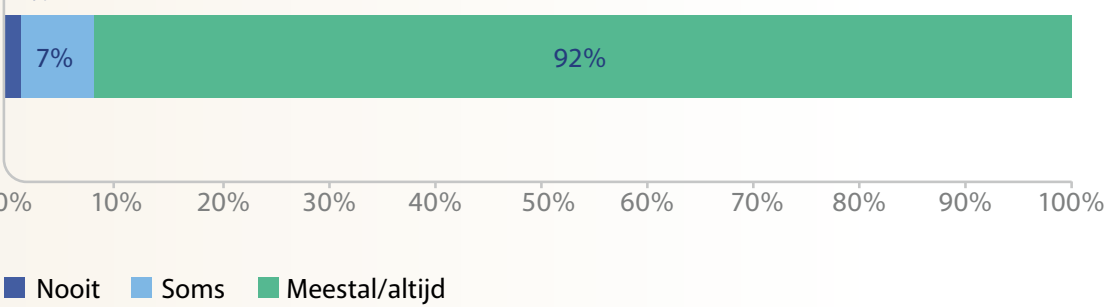




\section{Figuur 2}

De respondenten konden aangeven hoe ze over een aantal aspecten van het werk van huisartsen in Nederland dachten. Ze mochten maximaal vijf aspecten kiezen, en deze rangschikken. Wat ze het belangrijkst vonden, gaven ze de waarde 1 , wat ze daarna het belangrijkst vonden waarde 2 , enzovoort [ $n=745$, gewogen].

Hieronder staat een aantal aspecten van hoe huisartsen in Nederland werken. We willen graag weten wat $u$, als patiënt bij die huisartsen, belangrijk vindt

Ik vind het belangrijk dat...

...huisartsen deskundig zijn ...huisartsen betrokken zijn bij hun patiënten ...huisartsen hun patiënten kennen ...alle mensen naar een huisarts kunnen gaan ...patiënten op hun huisarts en zijn/haar team kunnen rekenen wanneer het nodig is ...huisartsen het overzicht houden over wat er met hun patiënten gebeurt

...huisartsen inspelen op de behoeften van hun patiënten ...huisartsen samenwerken in een team met andere zorgverleners ...huisartsen goede zorg leveren voor zieke mensen ...huisartsen constant bezig zijn met verbeteringen van hun vakgebied ...huisartsen onafhankelijk kunnen werken ...huisartsen klachten, problemen en vragen van alle mensen kunnen beantwoorden ...huisartsen eindverantwoordelijk zijn voor wat er in de huisartsenpraktijk gebeurt

...huisartsen alleen de zorg verlenen die nodig is ...huisartsen zich specialiseren (bijvoorbeeld in kleine operaties) ...huisartsen zelf kunnen kiezen hoeveel uren zij werken ...betrokken zijn bij problemen in de samenleving

Rangorde 1-5, 1 meest belangrijk, 5 minst belangrijk

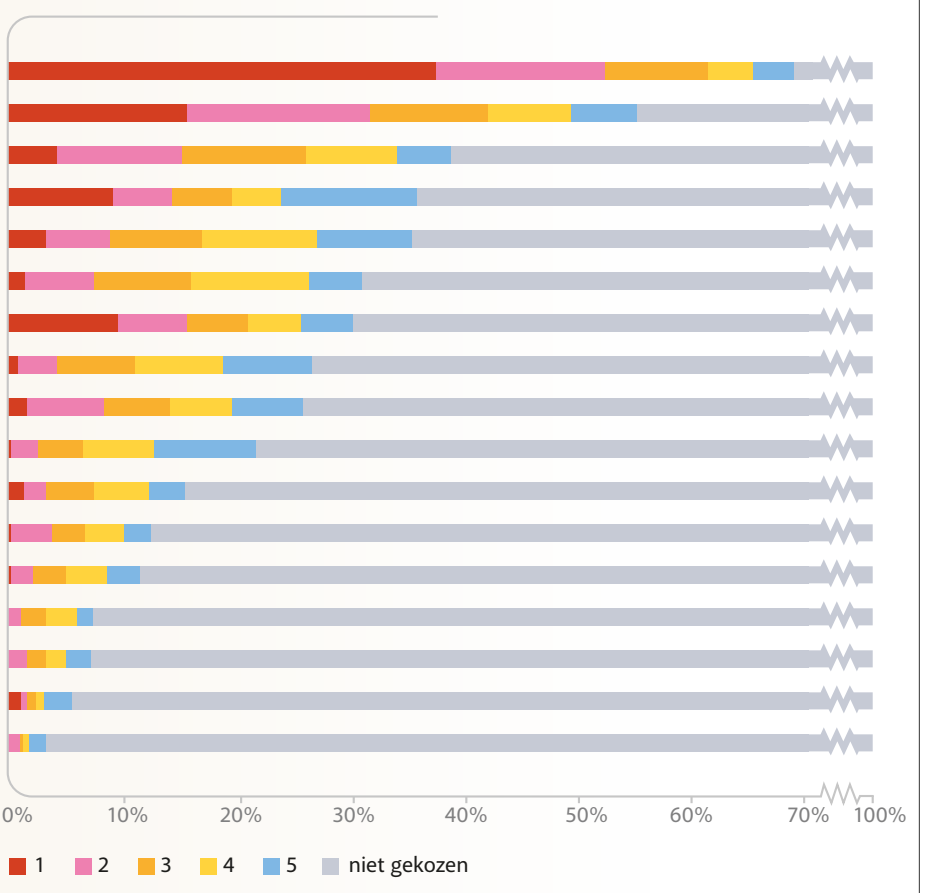

\section{Figuur 3}

Taken die volgens de respondenten ook door anderen kunnen worden gedaan wanneer de huisarts niet voldoende tijd heeft [n = 684, gewogen]

\section{Als de huisarts niet voldoende tijd heeft, vind ik dat de volgende taken ook door anderen kunnen worden gedaan..}

Eerste aanspreekpunt zijn voor mensen met vragen over sociale problemen, zoals financiële problemen of huisvestingsproblemen Voorkomen dat gezonde mensen ziek worden

De zorg tussen verschillende zorgverleners voor patiënten met een chronische ziekte coördineren

Patiënten tijdens alle consulten adviseren over gezondheid en leefstijl

Bijdragen aan het verminderen van verschillen in gezondheid tussen mensen in de wijk of in het dorp

Zorg verlenen aan stervende patiënten, buiten kantooruren

Huisartsenzorg bieden buiten kantooruren

De urgentie/belangrijkheid van klachten beoordelen

Vaststellen of patiënten moeten worden doorverwezen naar een medisch specialist

Samenwerken met andere zorgverleners in een team

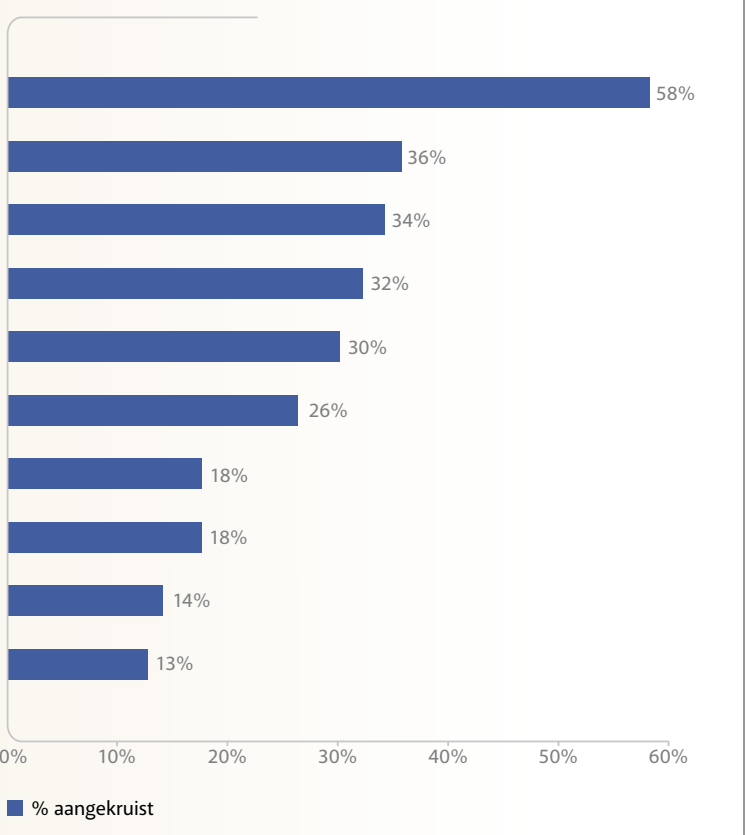




\section{Beschikbaarheid huisartsenzorg voor niet-spoedeisende en spoedeisende vragen}

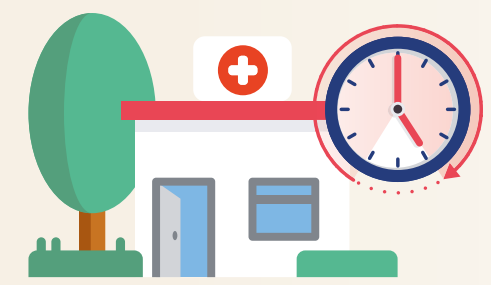

Ik wil dat huisartsenzorg voor niet-spoedeisende vragen ( $n=677$, gewogen)

Ik wil dat huisartsenzorg voor spoedeisende vragen $(n=676$, gewogen)
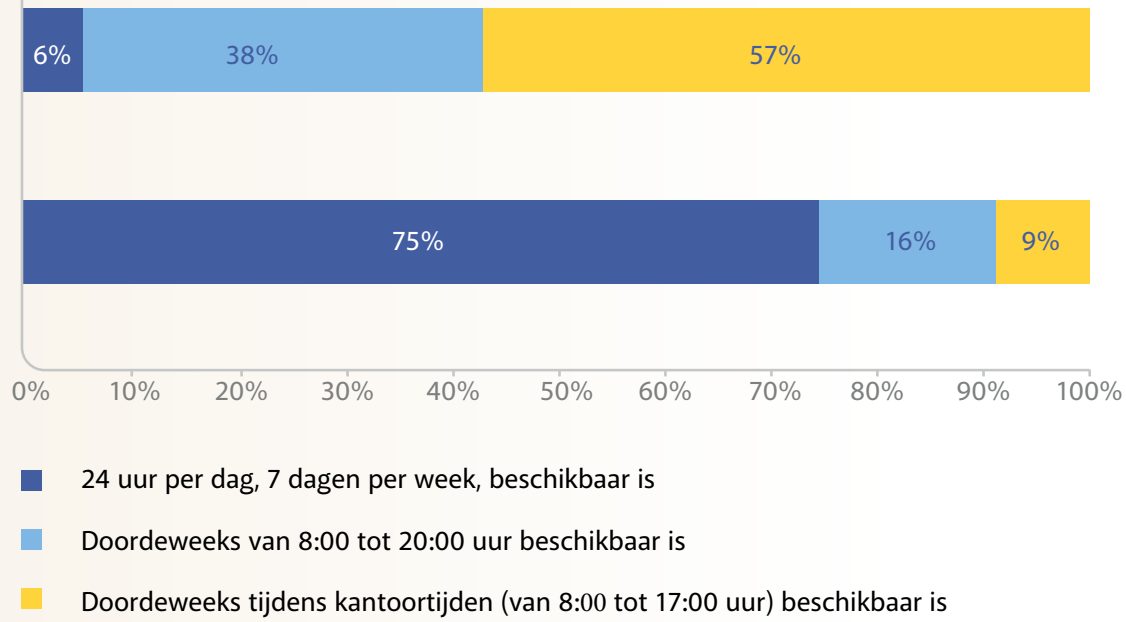

\section{Beschikbaarheid van de huisartsenzorg}

Van de respondenten wilde ruim de helft $(56,8 \%)$ dat huisartsenzorg voor niet-spoedeisende vragen doordeweeks tijdens kantoortijden beschikbaar is [figuur 4]. Bijna vier op de tien wilden dat voor dergelijke vragen huisartsenzorg doordeweeks van 8:00 tot 20:00 uur beschikbaar is. Bijna driekwart van de respondenten was van mening dat huisartsenzorg 24 uur per dag zeven dagen per week beschikbaar moet zijn voor spoedeisende vragen.

Met betrekking tot terminaal-palliatieve zorg vond ruim de helft $(55,5 \%)$ van de respondenten dat de huisarts zelf doordeweeks tijdens kantoortijden en daarbuiten op door de huisarts zelf gekozen tijdstippen beschikbaar moet zijn [figuur 5]. Verder was bijna vier op de tien van mening dat de huisarts zelf hiervoor 24/7 beschikbaar moet zijn.

\section{BESCHOUWING}

Uit de resultaten blijkt dat burgers over het algemeen ruim tevreden zijn over de huidige vormgeving van de huisartsenzorg en dat zij en huisartsen wat betreft de kernwaarden en kerntaken van de huisarts(enzorg) op één lijn zitten. Er zijn wel verschillen van inzicht met betrekking tot de invulling van palliatieve zorg en het meedoen aan wetenschappelijk onderzoek. Over het algemeen zijn de resultaten behoudend; op grond van de burgerenquête is er weinig verandering nodig. Dat is ook niet vreemd, want de respondenten zijn tevreden over de huidige situatie. Burgers blijken het vooral belangrijk te vinden dat huisartsen deskundig en betrokken zijn, en dat ze hun patiënten kennen. Dit sluit aan bij de resultaten van de enquête onder huisartsen, waaruit bleek dat ook huisartsen het leveren van goede zorg en het kennen van hun patiënten als essentie van het huisartsenvak zien.
Ook het opleiden van nieuwe huisartsen en meedoen aan wetenschappelijk onderzoek zien burgers als taken van de huisarts. Huisartsen zelf rekenen vooral het meedoen aan onderzoek veel minder tot hun kerntaken, zo bleek uit de huisartsenenquête; $72 \%$ van hen vindt dat alle huisartsen samen met universiteiten verantwoordelijk zijn voor het opleiden van nieuwe huisartsen en $46 \%$ geeft aan zelf als huisarts structureel mee te willen doen aan wetenschappelijk huisartsgeneeskundig onderzoek. Bedenk daarbij wel dat de respondenten van de burgerenquête, als deelnemer aan het Nivel Consumentenpanel Gezondheidszorg, mogelijk positiever aankijken tegen wetenschappelijk onderzoek dan de gemiddelde Nederlander.

\section{Burgers zijn over het algemeen ruim tevreden over de huidige huisartsenzorg}

Burgers vinden minder vaak dat huisartsen het eerste aanspreekpunt moeten zijn voor mensen met vragen over sociale problemen. Daarnaast zijn ze minder vaak van mening dat preventie tot de taken van de huisarts behoort. ${ }^{2,3}$ Uit de enquête onder huisartsen bleek dat ook de huisartsen zelf het oplossen van sociale problematiek en de uitvoering van populatiegerichte preventie niet tot hun kerntaken rekenen. Huisartsen zien zichzelf daarentegen wel als de aangewezen persoon voor het signaleren van sociale problemen en voor het bieden van geïndiceerde en zorggerelateerde preventie aan de individuele patiënt. De resultaten van de enquête onder huisartsen worden binnenkort gepubliceerd in het derde artikel van deze serie. 


\section{Figuur 5}

Beschikbaarheid van de huisarts zelf voor stervende patiënten [ $n=675$, gewogen]

\section{Beschikbaarheid huisarts zelf voor stervende patiënten}

Ik wil dat huisartsen zelf beschikbaar zijn voor hun stervende patiënten

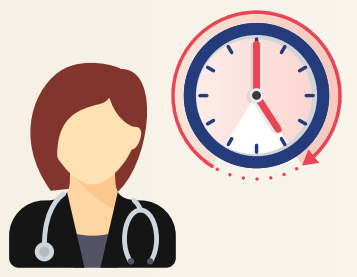

\section{(1)}

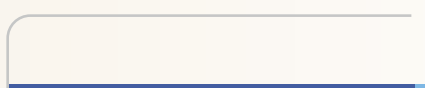

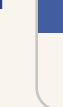

$38 \%$

$56 \%$

$0 \%$

$10 \%$

$20 \%$

$30 \%$

$40 \%$

$50 \%$

$60 \%$

$70 \%$

$80 \%$

$90 \% \quad 100 \%$

24 uur per dag, 7 dagen per week

Doordeweeks tijdens kantoortijden (van 8:00 tot 17:00 uur)

Doordeweeks tijdens kantoortijden en daarbuiten op door de huisarts zelf gekozen tijdstippen
Wanneer we kijken naar de beschikbaarheid van de huisartsenzorg wil ruim de helft van de burgers dat de huisartsenzorg voor niet-spoedeisende vragen doordeweeks tijdens kantoortijden beschikbaar is. In de huisartsenenquête gaf iets meer dan de helft (54\%) aan te vinden dat reguliere huisartsenzorg doordeweeks tijdens kantoortijden beschikbaar moet zijn. Voor spoedeisende vragen wil bijna driekwart van de burgers dat huisartsenzorg 24/7 beschikbaar is. Dit laatste strookt met zowel de herijkte kernwaarde 'continu' als de herijkte kerntaak 'spoedeisende huisartsenzorg'. Dit betekent dat huisartsenzorg 24 uur per dag beschikbaar is voor gezondheidsklachten die medisch gezien direct of binnen enkele uren moeten worden beoordeeld. ${ }^{3,4}$

\section{Burgers vinden het belangrijk dat huis- artsen deskundig en betrokken zijn}

Met betrekking tot terminaal-palliatieve zorg zien we een discrepantie tussen de mening van burgers en die van huisartsen. Ruim de helft van de burgers vindt dat de huisarts zelf doordeweeks tijdens kantoortijden en daarbuiten op door de huisarts zelf gekozen tijdstippen beschikbaar moet zijn voor terminaal-palliatieve zorg. Nog eens vier op de tien vindt dat de huisarts hiervoor zelf $24 / 7$ beschikbaar moet zijn. Uit de enquête onder huisartsen blijkt dat bijna driekwart vindt dat terminaal-palliatieve zorg tijdens kantoortijden en daarbuiten op door de huisarts zelf gekozen tijdstippen beschikbaar moet zijn (73,0\%). Verder vindt $22,0 \%$ van de huisartsen dat de huisarts zelf $24 / 7$ beschikbaar moet zijn. In de herijkte kerntaken staat dat huisartsen doordeweeks overdag terminaal-palliatieve zorg aan hun eigen patiënten bieden. Daar- naast zorgen ze ervoor dat terminaal-palliatieve zorg 24 uur per dag beschikbaar is. ${ }^{3}$

\section{Representativiteit van het onderzoek}

Een sterk punt van ons onderzoek is dat de burgerenquête is ingevuld door een grote groep burgers, ook al lag de respons net boven de 50\%. Daarnaast zijn de resultaten gewogen naar leeftijd en geslacht voor een betere representativiteit voor de algemene bevolking van achttien jaar en ouder in Nederland. Wel is het de vraag in hoeverre de resultaten van toepassing zijn op alle groepen patiënten. Ook al bestaat het Consumentenpanel Gezondheidszorg uit leden die een brede afspiegeling vormen van de bevolking (bijvoorbeeld laag- en hoogopgeleiden), toch ontbreken de kwetsbaarste groepen. Een voorbeeld hiervan zijn mensen die laaggeletterd zijn, voor wie deelname aan een schriftelijke vragenlijst een probleem vormt. Ook migranten zijn ondervertegenwoordigd binnen het panel. Het is mogelijk dat deze groepen anders aankijken tegen de kernwaarden en kerntaken van huisartsen. Om hier zicht op te krijgen zouden interviews afgenomen kunnen worden.

De burgerenquête is gemaakt op basis van de enquête voor huisartsen, wat betekent dat in de burgerenquête de kernwaarden en kerntaken zijn genoemd die uit de denksessies met huisartsen zijn gekomen. Voordeel hiervan is dat we de resultaten kunnen vergelijken: aan huisartsen en burgers zijn dezelfde kerntaken en kernwaarden voorgelegd. Nadeel is dat we niet weten of burgers heel andere kerntaken en kernwaarden van belang vinden, die niet door huisartsen zijn genoemd. Dit is voor een klein deel ondervangen doordat in de enquête aan de respondenten een open vraag is voorgelegd waarbij ze een aspect mochten toevoegen dat ze belangrijk vinden met betrekking tot huisartsen en dat niet genoemd was. De meest genoemde aspecten hadden te maken met het feit dat 
de huisarts tijd heeft voor de patiënt en dat de huisarts goed luistert. We zouden een completer beeld krijgen als we ook denksessies met burgers hadden gehouden en we de resultaten van zowel de denksessies met huisartsen als die met burgers in de enquêtes voor beide groepen hadden verwerkt.

\section{CONCLUSIE}

Samenvattend blijkt uit deze burgerenquête dat de opvattingen van burgers aansluiten bij de herijkte kernwaarden en kerntaken van de huisarts(enzorg). Burgers vinden het belangrijk dat huisartsen deskundig en betrokken zijn. Sociale problematiek en preventie zien ze minder als taak van huisartsen. Burgers vinden wel vaker dan huisartsen dat de huisarts persoonlijk voor terminale zorg beschikbaar moet zijn.

\section{LITERATUUR}

1. Brabers A, De Jong J. Toekomst van de huisartsenzorg. Het perspectief van de burger. Resultaten van een enquête onder burgers. Utrecht: Nivel, 2019.

2. Brabers AEM, Reitsma-van Rooijen M, De Jong JD. Consumentenpanel Gezondheidszorg. Basisrapport met informatie over het panel (2015). Utrecht: Nivel, 2015.

3. Toekomst Huisartsenzorg. Uitwerking kerntaken. Utrecht: NHG, 2019. https://www.toekomsthuisartsenzorg.nl.

4. Toekomst Huisartsenzorg. Uitwerking kernwaarden. Utrecht: NHG, 2019. https://www.toekomsthuisartsenzorg.nl.

Brabers AEM, De Wit N, Meijman HJ, De Jong JD. Wat beschouwen burgers als kernwaarden en kerntaken van de huisarts? Huisarts Wet 2019;62:D0l:10.1007/s121445-019-0290-9.

Nivel, Utrecht: dr. A.E.M. Brabers, senior onderzoeker, a.brabers@ nivel.nl; prof.dr. J.D. de Jong, programmaleider. UMC Utrecht, Julius Centrum Voor Gezondheidswetenschappen en Eerstelijns geneeskunde, Utrecht: prof.dr. N de Wit, hoogleraar Huisartsgeneeskunde. Actiecomité Het Roer Moet Om: H.J. Meijman, huisarts, lid actiecomité. Universiteit Maastricht, Vakgroep Health Services Research, CAPHRI, Faculteit Health, Medicine and Life Sciences, Maastricht: prof.dr. J.D. de Jong, bijzonder hoogleraar Zorgstelsel en Sturing. Mogelijke belangenverstrengeling: niets aangegeven. 